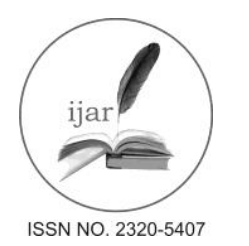

Journal homepage:http://www.journalijar.com

Journal DOI:10.21474/IJAR01

RESEARCH ARTICLE
INTERNATIONAL JOURNAL

OF ADVANCED RESEARCH

\title{
TO ASSESS THE COMPETENCE OF DENTAL STUDENTS AND RECENT DENTAL GRADUATES ON DEALING WITH CULTURAL BARRIERS AMONG THEIR PATIENTS.
}

\author{
Kirtana Gopalasamy ${ }^{1}$ and Kathiravan Selvarasu ${ }^{2}$. \\ 1. I BDS, Saveetha Dental College and Hospitals, No162, P.H Road, Chennai - 77. \\ 2. Senior Lecturer, Department of Oral and Maxillofacial surgery, Saveetha Dental College and Hospitals, No162, \\ P.H Road, Chennai - 77.
}

\section{Manuscript Info}

\section{Manuscript History:}

Received: 12 April 2016

Final Accepted: 19 May 2016

Published Online: June 2016

Key words:

cultural differences, competency, dental students training, culturally diverse patient

*Corresponding Author Kirtana Gopalasamy.

\begin{abstract}
Aim: -This was done to assess dental students and dental graduate's attitudes and knowledge on cultural competence and diversity training while treating his patients.

Background: -Recent developments have emphasised the need for dental students and dental graduates to be prepared to address the needs of a diverse patient population. Underlying these developments was the understanding to see how well prepared the students are to be competent in meeting the needs of a diverse patient population.

Materials and methods: - 200 Dental students and graduates were asked to complete a questionnaire of 15 questions assessing their competence towards their culturally diverse patient. They were also assessed on how well they were able to cope up with the diversity and establish a good doctorpatient relationship to provide quality oral-healthcare.

Reason: -This research was carried to see how well trained and competent a dental students and graduates are while treating his culturally diverse patients. This research also asses how well trained he is to overcome culturally diverse patient population to provide quality oral health care and benefit their patient regardless of it.
\end{abstract}

Copy Right, IJAR, 2016,. All rights reserved.

\section{Introduction: -}

Interaction between a health care provider and a patient is key to successful treatment. This is the very build up of the dental treatment [1] . Assessment of medical and dental education has traditionally mostly relied on testing students' ability to acquire and maintain facts and very little on the practical usage [2].In recent times, however, the crucial part of the health care professionals education is mostly recognised through the attainment of appropriate interpersonal communication skills[5]. Communication training is the most effective when taught or carried out to implement within predoctoral education. Quality health care also requires understanding of cultural values, traditions, health-related beliefs, and attitudes of the many cultural groups seeking professional care [6].

Recent developments have emphasised the need for dental students to be prepared to address the needs of a diverse patient population. Standardised formal training in cultural competence is clearly needed across health professions schools [14]. Underlying these developments was the understanding that the preparation of students who are competent in meeting the needs of a diverse patient population has implications for oral health care access and quality of care.

Hence this questionnaire based study was done to assess the competence of dental students on dealing with cultural barriers among their patients. 


\section{Methods and materials: -}

A cross sectional questionnaire surveywas carried outto assess the competence of dental students on dealing with cultural barriers among their patients.A Convenient sample size of 200 dental students was decided and data was collected by questionnaire. This questionnaire was approved by the scientific research board of SAVEETHA dental college. A specially designed questionnaire consisting of 13 close ended questions was said to assess the competence of dental students on dealing with cultural barriers among their patients. This questionnaire was made to answer in a scale of 1-5. The qualitative component was added by introducing one open-ended question to which participants were asked to share their opinions. this questionnaire was later distributed to the undergraduate and recent postgraduate dental students in Chennai. The name and Identity of the students was maintained anonymous.all the students were given a half an hour to one hour time to complete the questionnaire the completed questionnaire were immediately collected and were analysed.

The questionnaire which was used for the survey has been attached below: 


\section{SAVEETHA DENTAL COLLEGE}

Questionnaire-To asses the competence of dental students on dealing with cultural barriers among their patients .

Note: Each question offered five possible answers

$1=$ very bad

$2=$ not very,

$3=$ somewhat,

YEAR-

4=fairly,

$5=$ very.

1. How competent are you communicating effectively with patients of different cultural groups?

2. How skilled do you usually feel in understanding a patient's non-verbal cues or gestures?

3. How comfortable are you in caring for patients with limited English proficiency?

4. How competent are you in being sure that the patient understands the dental diagnosis?

5. How competent are you in involving the patient's family during the procedure/treatment .

6. How competent are you with the level of involvement of the patient's family in the treatment decision making process?

7. To what extent do you think sociocultural differences can affect the provision of quality dental care?

8. How often do you encounter difficulty in establishing rapport with a patient?

9. How competent are you dealing with a patient's cultural beliefs that may interfere with diagnosis and treatment?

10. How competent are you dealing with a patient's non-compliance with recommended oral home care?

11. How useful are lectures/tutorials for teaching sociocultural skills in the dental program?

12. How important is development of communication skills for culturally diverse dental practice?

13. Are there any other sociocultural situations in which you experience problems in dealing with patients of a different cultural group?

FIGURE 1- Questionnaire used for assessing the students. 
Data analysis:-

The data entry was done by Microsoft Excel. The collected data was analysed using descriptive analysis.

In the study:-

Table 1:- shows the number of students from each year who have answered the questionnaire.

\begin{tabular}{|c|c|}
\hline Year of Study & No. Of students \\
\hline $3^{\text {rd }}$ years & 5 \\
\hline $4^{\text {th }}$ years & 90 \\
\hline Interns & 60 \\
\hline Post Graduates & 45 \\
\hline
\end{tabular}

Figure 2:- Graphical analysis of the year of study of the students.
Year of study
Brd years
4th years:
Interns
Post graduates

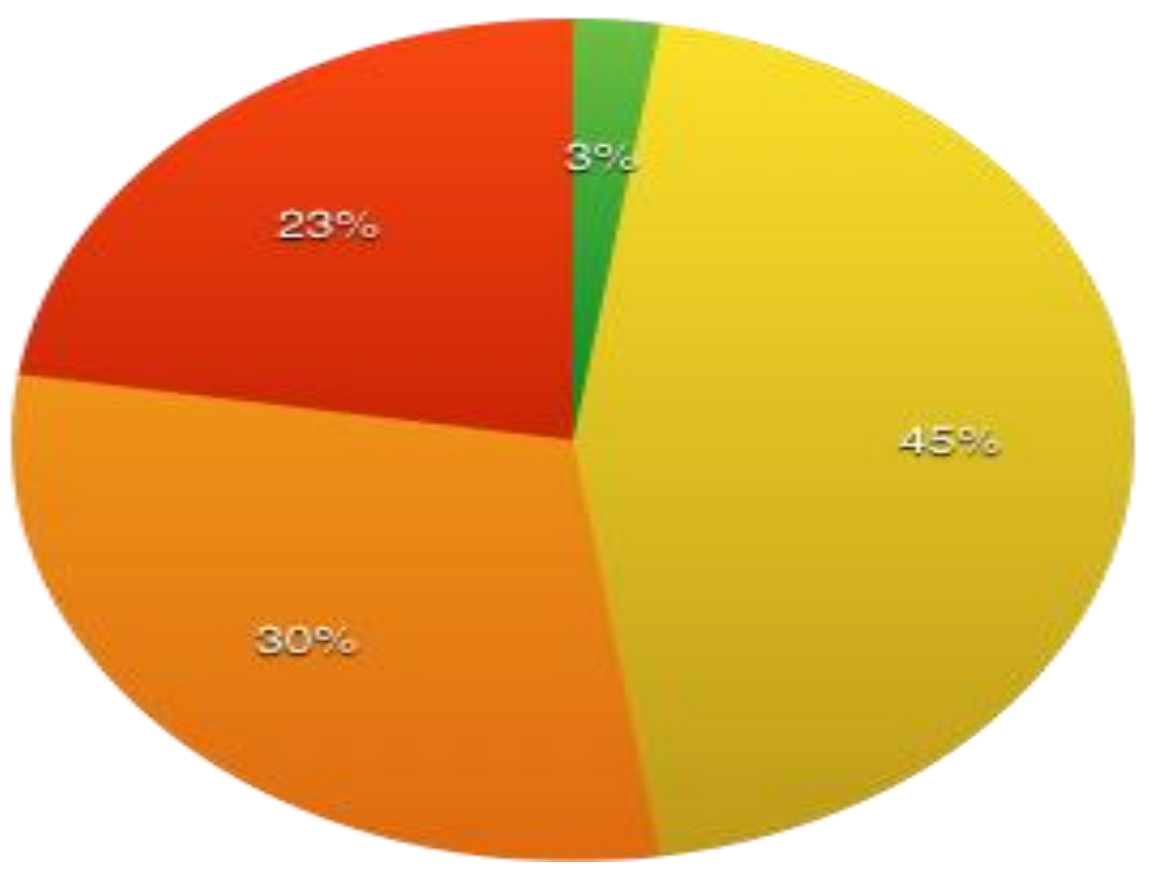

Question 1- Question 12 have represented in the bar graph:-

Table 1:- tabulation of the data of question 1 to question 12 from the questionnaire.

\begin{tabular}{|c|c|c|c|c|c|}
\hline & 1 & 2 & 3 & 4 & 5 \\
\hline Question 1 & 10 & 15 & 54 & 81 & 40 \\
\hline Question 2 & 13 & 37 & 64 & 78 & 8 \\
\hline Question 3 & 7 & 18 & 54 & 71 & 50 \\
\hline Question 4 & 11 & 30 & 83 & 59 & 17 \\
\hline Question 5 & 17 & 28 & 87 & 54 & 14 \\
\hline Question 6 & 20 & 44 & 64 & 57 & 15 \\
\hline Question 7 & 8 & 42 & 64 & 71 & 15 \\
\hline Question 8 & 30 & 94 & 45 & 20 & 11 \\
\hline Question 9 & 7 & 40 & 87 & 53 & 13 \\
\hline Question 10 & 6 & 40 & 68 & 82 & 4 \\
\hline Question 11 & 12 & 30 & 59 & 75 & 24 \\
\hline Question 12 & 3 & 23 & 40 & 54 & 80 \\
\hline
\end{tabular}


Figure 3:-Graphical Analysis of the Data from Question 1 to Question 12.

\section{Qualitative Data Assessment}

ㅁ 1
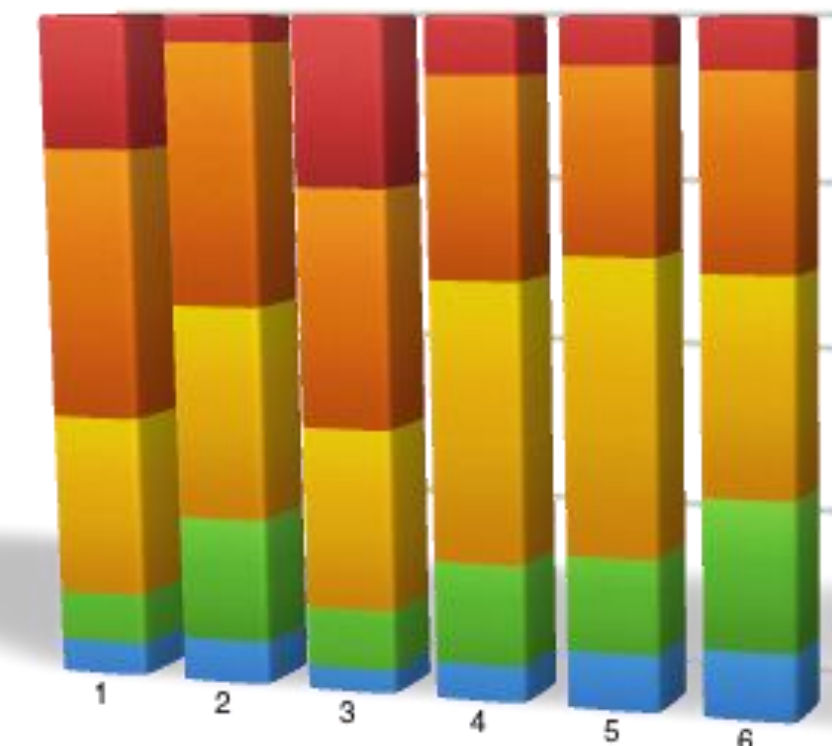

6
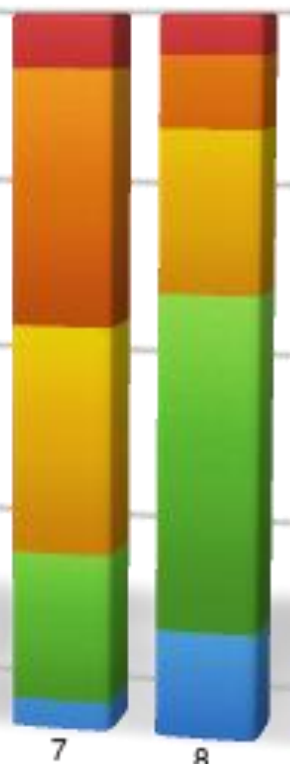

8

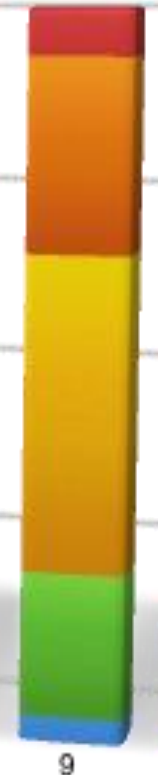

9

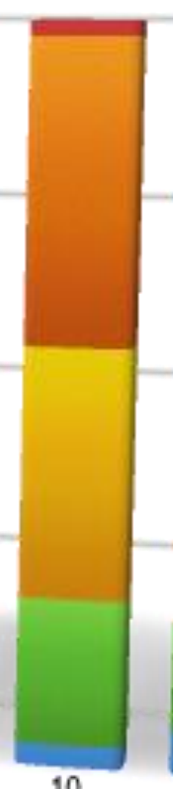

10

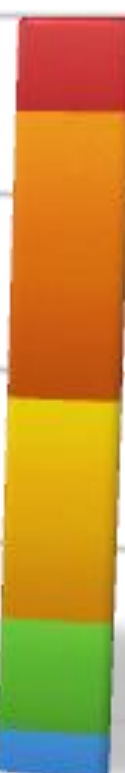

11

13th question:-

The question was related to students' experience of culturally challenging situations.

This dealt with the problems related to communication challenges experienced by students in culturally related situations.Students mainly gave the following answers as to what were the other sociocultural situations and issues they deal with while treating their patients.

Table 3:- Tabulation of the data of Question 13.

\begin{tabular}{|c|c|}
\hline Issues faced & No.of students \\
\hline 1.Communication is a problem. & 10 \\
\hline 2.Interpreting does not always work. & 25 \\
\hline $\begin{array}{c}\text { 3. When patient's first language is not English and they } \\
\text { are asked to describe something such as pain. }\end{array}$ & 20 \\
\hline $\begin{array}{c}\text { 4.communication is a big problem in getting information } \\
\text { across, not being sure if patients understand. }\end{array}$ & 30 \\
\hline $\begin{array}{c}\text { 5.Communicating on the phone regarding appointments } \\
\text { is difficult. }\end{array}$ & 40 \\
\hline $\begin{array}{c}\text { 6.Difficulties in explaining a procedure. } \\
\text { 7.Sometimes I feel some patients are not happy with my }\end{array}$ & 60 \\
\hline
\end{tabular}


Figure 4:- Graphical Analysis of Question 13.

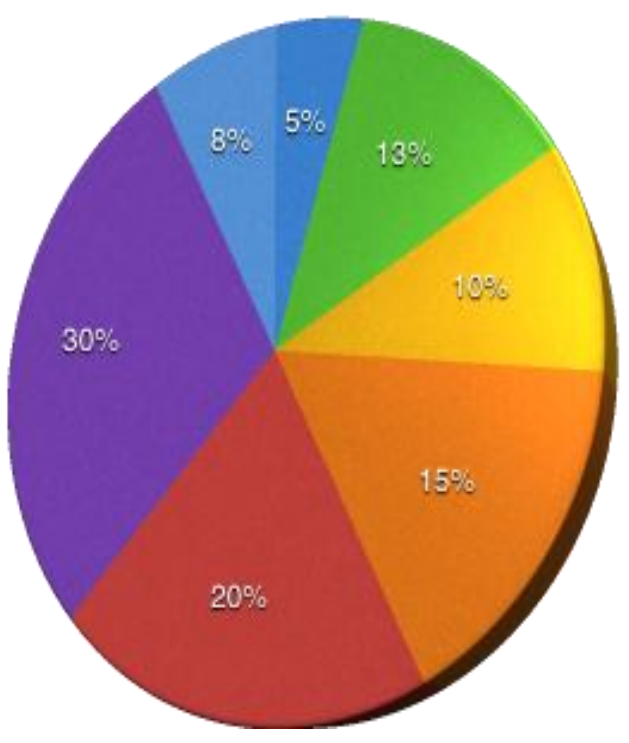

1.Communication is a problem.

2.Interpreting does not always work.

3.When patient's first language is not English and they are asked to describe something such as pain.

4.communication is a big problem in getting information across, not being sure if patients understand.

5.Communicating on the phone regarding appointments is difficult.

6.Difficulties in explaining a procedure.

7.Sometimes I feel some patients are not happy with my accent.

\section{Result:-}

The extent to which the competence and ability among dental students and recent dental graduates progressively increases from 4th year students towards interns and to the recent Post Graduates then when compared to the third years This can be attributed to increased experience on overcoming the cultural barriers while treating their patients. This can also be attributed due to the increased exposure to many patients with cultural barriers and treating them.

\section{Discussion:-}

This cross sectional study was conducted to assess the competence of dental students and recent dental graduates on dealing with cultural barriers among their patients about 200 dental students were interviewed with a structured questionnaire .This study discusses mainly about how important it is for a dental student or a graduate to overcome the cultural barriers in order to completely treat a patient without any issues and hurdles.

Among the study conducted it has been found that about $40.5 \%$ of the students fairly competent in communicating efficiently with patients of different cultural groups. About $64.6 \%$ of the students and recent graduates are somewhat skilled in understanding the patients non verbal cues or gestures. About $35.5 \%$ of the students and recent graduates are fairly comfortable in caring for patients with limited English proficiency. About $41.5 \%$ of the students and recent graduates are somewhat competent in being sure that the patient understands the dental diagnosis also about $43.5 \%$ of the students who took the survey said that they were somewhat competent in involving the patient's family during the course of treatment. About 32\% of the students and recent graduates said that they were somewhat comfortable at the involvement of the patient's family in the treatment decision making process. And about $35.5 \%$ of the students and recent dental graduates thought that sociocultural differences can fairly affect the provision of quality dental care. About $47 \%$ of the students and recent graduates felt somewhat difficult in establishing a rapport with the patient also about $43.5 \%$ felt somewhat competent enough to in dealing with the patients cultural belief that may interfere with diagnosis and treatment .we also see that about $41 \%$ are fairly competent in dealing with the patients non compliance in the recorded oral health care. About $37.5 \%$ of the study's and recent graduates felt that the lectures and tutorials for teaching sociocultural skills were fairly useful in the dental program and practice and we also see that about $40 \%$ of them felt that it is extremely important for the development of communication skills for diverse dental practice. Also almost $30 \%$ of the students and recent graduates who took part in this survey replied back saying that explaining the procedure or diagnosis to the patients was very difficult and many were not competent enough in doing so . 
Even the dentist's behaviours during the treatment majorly affect the Behaviour of the patient during the treatment. [12]

From the survey conducted we were also able to notice that As expected the third-year students, who had minimal experience in treating patients, and the fourth-year students, who had a substantial number of encounters with patients. Unsurprisingly, the third-year students reported higher levels of deficiency in cultural competence as compared to their fourth-year counterparts. The most significant differences we observed were between the students and recent graduates. Recent graduates as compared to dental students seemed to be more confident in caring for patients with limited English proficiency, had more frequently encountered involvement of the patient's family in the treatment decision making process, and were more skilled in eliciting information on the patient's dental needs and concerns, negotiating a treatment plan, or interpreting different cultural expressions of pain and suffering [1].

Our survey supports the need for an increased focus to teach cultural competence in predoctoral dental curriculam. The dental students in our study identified a number of specific deficiencies in their cultural competence, such as challenges inherent in intercultural communications, lack of understanding of culturally based beliefs, and cultural attitudes impeding on professional health care as well as patient compliance. The majority of the participants acknowledged the importance of cultural competence, expressed a need for more training, and suggested topics for teaching the subject.

While there is a published definition of cultural competence and it is widely understood that training in cultural competence is important and necessary [2, 28]. Rowland et al.[3] reported that, at a small number of schools (six of the thirty-four schools participating), the topic was taught in a separate course, while the majority of these schools indicated that cultural competence was presented in several different courses in the school's curriculum. Similarly, Saleh et al.[4] found that the majority of dental schools presented these issues in more than one course in the curriculum, although that method of delivery was associated with less thorough coverage of the topic than was instruction at schools where there was a dedicated course for the topic. Both studies reported little consistency across schools in topics covered or where these topics were located in the curriculum [9].

Teaching culturally sensitive care is particularly difficult to implement in a dental school environment; it requires a change in perspective for both students and instructor [2]. This show as that teaching cultural competency in the developing future dental professions is extremely important.[9]

\section{Conclusion:-}

From the present study we can conclude that dental students play an important role in the oral health of the patient and that the undergraduate dental student or the recent dental graduate must have the competence, ability and even the knowledge to deal and to overcome the cultural barriers while treating their patients in order to provide quality oral health care. Majority of the participants also acknowledged the importance of cultural competence and expressed a need for more training on overcoming the cultural barriers[3].therefore we see that teaching cultural competency in future dental professions is extremely important and is off at most importance to the students while practicing dentistry. 


\section{References:-}

1. JolantaAleksejuniene, Ph.D. , Chris Zed, Ph.D. and Rodrigo Marino, Ph.D. Self-Perceptions of Cultural Competence Among Dental Students and Recent Graduates

2. Evelyn Donate-Bartfield, Ph.D. «, William K. Lobb, D.D.S., M.S., M.P.H. and Toni M. Roucka, D.D.S., M.A. Teaching Culturally Sensitive Care to Dental Students: A Multidisciplinary Approach

3. Rowland ML, Bean CY, Casamassimo PS. A snapshot of cultural competence in U.S. dental schools. J Dent Educ 2006;70(9):982-90.

4. Saleh L, Kuthy RA, Chalkley Y, Mescher KM. An assessment of cross-cultural education in United States dental schools. J Dent Educ 2006;70(6):610-23.

5. Commission on Dental Accreditation. Self-study guide for dental education programs: accreditation standards adopted on August 6, 2010. At: www.ada.org/sections/educationAndCareers/pdfs/predoc_ssg_2012.pdf. Accessed: June 24, 2012.

6. American Dental Education Association. ADEA policy statement: recommendations and guidelines for academic institutions. J Dent Educ 2011;75(7):957-68.

7. Sunila B. Sangappa, M.D.S., P.G.D.H.P.E. $\Uparrow$ and Ara Tekian, Ph.D., M.H.P.E.Communication Skills Course in an Indian Undergraduate Dental Curriculum: A Randomized Controlled Trial

8. Pine CM, McGoldrick PM. Application of behavioral sciences teaching by UK dental undergraduates. Eur J Dent Educ 2000;4(2):49-56.

9. White JG, Krüger C, Snyman WD. Development and implementation of communication skills in dentistry: an example from South Africa. Eur J Dent Educ 2008; 12(1):29-34.

10. Jackson E. The role of behavioral science in dental education. BehavEduc Dent 1986;8:23-6.

11. Kulich KR, Berggren U, Hallberg LR. Model of the dentist-patient consultation in a clinic specializing in the treatment of dental phobic patients: a qualitative study. ActaOdontolScand 2000;58(2):63-71.

12. Kersten HW. The enhancement of learning by teaching. Eur J Dent Educ 1997;1(4):149-52.

13. Kolb YA, Kolb YD. Learning styles and learning spaces: enhancing experiential learning in higher education academy of management. Learn Educ 2005;4(2):193-212.

14. Dolhun EP, Munoz C, Grumbach K. Cross-cultural education in U.S. medical schools: development of an assessment tool. Acad Med 2003;78(6):615-22.

15. Dolhun EP, Munoz C, Grumbach K. Cross-cultural education in U.S. medical schools: development of an assessment tool. Acad Med 2003;78(6):615-22.

16. Like RC. Educating clinicians about cultural competence and disparities in health and health care. J ContinEduc Health Prof 2011;31(3):196-206.

17. Rowland ML, Bean CY, Casamassimo PS. A snapshot of cultural competency education in U.S. dental schools. J Dent Educ 2006;70(9):982-90.

18. Tulman L, Watts RJ. Development and testing of the blueprint for integration of cultural competence in the curriculum questionnaire. J Prof Nurs 2008;24:161-6. 